\title{
UMA VELA A DEUS, OUTRA AO DIABO: A (IN)SUSTENTÁVEL POLÍTICA PARA MUDANÇAS CLIMÁTICAS DO GOVERNO BRASILEIRO E AS RESPOSTAS DA SOCIEDADE CIVIL
}

\author{
João Alfredo Telles Melo \\ Advogado. Mestre em Direito Público pela Universidade Federal \\ do Ceará. Professor de Direito Ambiental na FA7. Consultor do \\ Greenpeace Brasil. \\ joaoalfredotellesmelo@gmail.com
}

Sumário: Introdução. 1) O aquecimento global, a espécie humana e a injustiça socioambiental. 2) O Brasil e as mudanças climáticas: contribuição e impactos. 3) A Amazônia no centro do aquecimento global: sumidouro e emissor de carbono. 4) O estado e o capital, de mãos dadas, quase sempre, no ataque à floresta. 5) Governo Lula: desenvolvimentismo insustentável versus resistência ambientalista (enxugando gelo em tempos de aquecimento global). 6) À guisa de conclusão: uma visão em perspectiva da luta socioambiental as propostas para a crise e as novas alianças que se tecem. 7) Posfácio: queda de Marina acentua contradições.

Resumo: O artigo analisa a política ambiental do governo do Presidente Lula da Silva em sua interface com a política de desenvolvimento e as propostas para a questão das mudanças climáticas, com acento na questão do aquecimento global, a partir do último relatório do Painel Intergovernamental de Mudanças Climáticas (o IPCC, em sua sigla em inglês) e os seus impactos no Brasil. Essa abordagem será mais focada na questão da Amazônia, em face da importância da preservação da floresta, não só por ser um imenso sumidouro de gás carbônico, mas também para o clima e o regime das chuvas em toda a América do Sul. Sem esquecer, entretanto, ainda que não mereça um tratamento mais demorado, a questão da matriz energética, inclusa no chamado Plano de Aceleração do Crescimento (o PAC). Essa abordagem não desconhecerá, no entanto, nem as ações nem as propostas dos movimentos ecológicos, sociais e socioambientais, como protagonistas que 
são da defesa da floresta. Antes pelo contrário, se dará voz à sociedade civil, por meio de um olhar em perspectiva, no fechamento deste texto.

Palavras-chave: Meio Ambiente; Mudanças Climáticas; Política Ambiental; Amazônia.

\section{INTRODUÇ̃̃o}

O presente texto pretende fazer uma análise, ainda que sucinta e não conclusiva, da política ambiental do governo do Presidente Luis Inácio Lula da Silva, atualmente em seu segundo mandato, abordando suas interfaces com a política de desenvolvimento e, principalmente, na sua relação com a questão das mudanças climáticas.

Inicialmente, se abordará o tema das mudanças climáticas, com acento evidentemente na questão do aquecimento global, a partir do último relatório do Painel Intergovernamental de Mudanças Climáticas (o IPCC, em sua sigla em inglês), os seus impactos no Brasil, com uma abordagem mais focada na questão da Amazônia, em face da importância da preservação da floresta, não só por ser um imenso sumidouro de gás carbônico, mas também para o clima e o regime das chuvas em toda a América do Sul.

Uma vez que, segundo os dados do último Inventário Nacional das Emissões de Gases do Efeito Estufa, 75\% dessas liberações advém das mudanças do uso do solo (em especial, pelas queimadas e desmatamentos), a questão dos impactos das políticas governamentais sobre a região terá um tratamento mais acentuado do que as demais regiões situadas nos outros biomas brasileiros. Isso sem esquecer ainda que não mereça um tratamento mais demorado a questão da matriz energética, inclusa no chamado Plano de Aceleração do Crescimento (o PAC).

O manejo, neste trabalho, da questão ambiental vis a vis a política voltada para a questão das mudanças climáticas por parte do governo federal se voltará mais para o âmbito das políticas internas em especial na contradição desenvolvimento versus proteção ambiental do que propriamente em analisar a atuação do país nos fóruns internacionais, em especial, no que concerne às reuniões das conferências das partes (COP) da Convenção Quadro das Nações Unidas sobre Mudanças do Clima e do Protocolo de Quioto. A compreensão do que se passa hoje no país em termos de política desenvolvimentista é a chave para entender a postura da diplomacia brasileira, no campo das mudanças climáticas.

A escolha dessa metodologia é coerente com o título desse artigo "uma vela a Deus, outra ao diabo" uma vez que se pretende abordar as profundas e, algumas vezes, insanáveis, contradições existentes no interior, nas propostas e nas ações do governo brasileiro, no que concerne à sua política de desenvolvimento e meio ambiente. 
A convivência, na equipe de governo, de um símbolo da luta ambientalista no planeta, como é a Ministra do Meio Ambiente, Marina Silva, com um dos mais lídimos, preparados e agressivos quadros do agronegócio brasileiro, como foi o Ministro Roberto Rodrigues, da Agricultura, tem produzido um embate permanente (e, por vezes, surdo) entre duas visões diversas e antagônicas. Isto tem levado, muitas vezes, a 'pretensas' soluções de conciliação que se chocam frontalmente com o que têm proposto, nas últimas décadas, os movimentos sociais e ecológicos no país e ao não enfrentamento das reais causas que têm produzido a degradação dos biomas brasileiros, que, em última análise colocam nosso país no incômodo posto de quarto ou quinto maior emissor de gases do efeito estufa (GEE).

\section{O AQUECIMENTO GLOBAL, A ESPÉCIE HUMANA E A INJUSTIÇA SOCIOAMBIENTAL}

Autor de um dos livros mais importantes para os ecossocialistas ${ }^{1}$, John Bellamy Foster, em artigo recente, intitulado A Ecologia da Destruição ${ }^{2}$ nos chama a atenção para o fato de que "é uma característica da nossa época que a devastação global pareça sobrepor-se a todos os outros problemas, ameaçando a sobrevivência da terra como a conhecemos".

A extraordinária repercussão do quarto relatório do $\mathrm{IPCC}^{3}$, em que milhares de cientistas de praticamente todo o planeta, não só constataram a relação direta entre fenômenos climáticos intensos decorrentes do aquecimento global com a emissão dos chamados gases de efeito estufa (GEE) pelas atividades industriais, energéticas e agrícolas, mas também apontaram projeções catastróficas para este século, caso não haja uma drástica mudança na matriz energética e no padrão de consumo deu foros de cientificidade ao documentário "A Verdade Inconveniente", do ex-vice-presidente estadunidense Al Gore, que recebeu o Oscar deste ano e também, juntamente com o próprio IPCC, o prêmio Nobel da Paz.

Por conseguinte, com exceção da minoria dos chamados "céticos", dentre os quais se encontram evidentemente, de forma involuntária - cientistas sérios ${ }^{4} \mathrm{e}$ organizações bancadas pelo Governo Bush e pelas grandes corporações de petróleo e carvão mineral no mundo, há uma ampla maioria de gente da comunidade científica $^{5}$, dos movimentos ambientalistas, de governos e até mesmo de setores

1 FOSTER, JOHN BELLAMY. “A Ecologia de Marx, Materialismo e Natureza”, Civilização Brasileira: Rio de Janeiro, 2005.

2 . A Ecologia da Destruição. In.: Revista Eletrônica O Comuneiro, no 4, março, 2007.

Disponível em: http://www.ocomuneiro.com/nr4_01_artigos_JOHN_BELLAMY.html

Sobre IPCC e sobre o quarto relatório, Climate Change 2007, consultar: http://www.ipcc.ch

4 A exemplo do grande geógrafo brasileiro Aziz Ab'Saber.

5 Destacam-se, nesse sentido, brasileiros da maior respeitabilidade, como José Goldenberg, Carlos Nobre e Luis Pinguelli Rosa. 
empresariais que, a partir dos dados do IPCC, procuram encontrar saídas para a crise planetária, manifestada hoje pelo aquecimento global que ameaça a vida na Terra.

Penso que, dada à ampla divulgação que a imprensa tem concedido ao tema, não seja mais necessário ter que detalhar, mas, tão somente, listar, em parte, o extenso e impactante elenco de fenômenos climáticos e de suas resultantes sobre a vida no planeta, como o acréscimo da temperatura média da terra, o derretimento das geleiras e calotas polares, a desaparição de espécies, a subida do nível do mar, a desertificação e a intensificação de secas e enchentes e seus profundos impactos sobre a humanidade, que poderá conviver aliás, já está convivendo - com os chamados 'refugiados ambientais'".

Nas palavras do físico brasileiro, professor da Universidade de São Paulo e membro do IPCC, Paulo Artaxo ${ }^{7}$,

"o que está acontecendo com o nosso planeta é que o homem adquiriu tal predomínio, como espécie dominante que vários dos processos naturais biogeoquímicos que governam a composição da atmosfera e o funcionamento dos ecossistemas, ao longo dos últimos 4,5 bilhões de anos de evolução do nosso planeta, estão sendo profundamente alterados pelo homem. Particularmente nos últimos 150 anos”.

$\mathrm{Ou}$, em outras palavras, "os seres humanos se converteram em força da natureza" (LuBCHENKO apud GONÇALVES ${ }^{8}, 2006$, p. 42).

Essa força (destrutiva) da espécie humana transparece no relatório-síntese sobre o aquecimento global, em que os cientistas do IPCC, reunidos em Valência, fizeram um grave alerta: "as mudanças podem ser rápidas e irreversíveis". O terceiro capítulo do documento, que trata das "mudanças climáticas e seus impactos em médio e longo prazo, sob diferentes cenários", se voltou para as prováveis alterações a partir do intervalo entre o cenário otimista de $1^{\circ} \mathrm{C}$ e o cenário de $5^{\circ} \mathrm{C}$ de acréscimo na temperatura média da terra (que ainda não é a pior projeção, que é de até $6,4^{\circ} \mathrm{C}$ ), até o final do século XXI. Observem-se os riscos a que o planeta está sujeito, segundo essas projeções (NETTO, 2007):

- Acréscimo de $1^{\circ} \mathrm{C}$ : O derretimento das geleiras ameaçará o suprimento de água para 50 milhões de pessoas; cerca de $80 \%$ dos recifes de coral em todo o globo morrerão; aumentam os danos costeiros causados por inundações e tempestades;

6 Vítimas de enchentes, tornados, secas, furacões, que, nos últimos tempos, têm atingido populações tão diversas como as asiáticas, as das pequenas ilhas do Pacífico, ou mesmo, nas terras do Império Americano, com o Katrina, em New Orleans, e o incêndio que devastou a Califórnia, ultimamente.

7 In.: Revista Caros Amigos, especial "Aquecimento Global”, ano XI, n. 34, set., 2007, p. 4 .

8 In.: Revista Sem Terra, “Aquecimento Global e Mudança Climática Global”, ano X, n. 36, nov-dez/06, p. 42. 
- Acréscimo de $2^{\circ} \mathbf{C}$ : A produção de cereais na África tropical cairá até $10 \%$; até $30 \%$ das espécies de seres vivos serão ameaçadas de extinção e a camada de gelo da Groenlândia começará a derreter de forma irreversível;

- Acréscimo de $3^{\circ} \mathrm{C}$ : Entre 1 bilhão e 4 bilhões de pessoas a mais enfrentarão falta de água; entre 1 milhão e 3 milhões de pessoas a mais morrerão de desnutrição e haverá início do colapso da floresta amazônica;

- Acréscimo de $4^{\circ} \mathrm{C}$ : As safras de produtos agrícolas diminuirão entre $15 \% \mathrm{e}$ $35 \%$ na África e até 80 milhões de pessoas a mais serão expostas à malária no continente; até $40 \%$ dos ecossistemas no mundo serão afetados;

- Acréscimo de $5^{\circ} \mathbf{C}$ : Grandes geleiras desaparecerão; a elevação do nível dos oceanos ameaçará locais como Londres e Tóquio; o sistema de saúde sofrerá uma sobrecarga com o aumento do número de casos de afetados.

Aquele documento afirmava que todos os países, de forma geral, seriam afetados pelos impactos das mudanças climáticas. No entanto, o Programa das Nações Unidas para o Desenvolvimento (PNUD), ao lançar o "Relatório de Desenvolvimento Humano 2007-2008", intitulado Combater a mudança do clima: Solidariedade Humana em um mundo dividido ${ }^{9}$, adverte para o fato de que:

“o mundo caminha para um ponto em que os países e os cidadãos mais pobres podem ficar permanentemente aprisionados em uma espiral de pobreza, em que centenas de milhões de pessoas terão dificuldades crescentes de garantir sua sobrevivência, escapar da desnutrição, convivendo progressivamente com falta de água e com desequilíbrios ecológicos" (ONU. PNUD, 2007).

Nas palavras de Kemal Dervis, administrador do PNUD:

"Em última instância, a mudança do clima é uma ameaça para o mundo, como um todo. Mas são os pobres, aqueles que não têm responsabilidade pelo débito ecológico em que nos encontramos, que se deparam com os custos humanos mais severos e mais prementes" (ONU. PNUD, 2007).

É o desenvolvimento desigual e combinado do sistema capitalista que acaba por gerar e distribuir, também de forma desigual e combinada, os impactos sociais e ambientais das mudanças climáticas por todo o planeta.

9 Disponível em www.pnud.org.br/rdh 
A desigualdade saltou evidente e mensurável quando ecólogos e economistas da Universidade de Califórnia, em Berkeley (EUA), liderados por Richard Norgaard, constataram que o:

\begin{abstract}
"dano ambiental que ações de países desenvolvidos causaram aos países em desenvolvimento é maior do que a dívida externa da ala pobre do mundo (...). O consumo e a destruição de recursos da natureza por parte dos ricos entre as décadas de 1960 e 1990 deverá impor ao longo do século 21 uma perda de US\$7,4 trilhões da economia de países de renda per capita baixa e média. A dívida externa dos países pobres na mesma época atingiu US\$ 1,7 trilhão"10.
\end{abstract}

Essa pesquisa quantificou o dano ambiental que foi causado à humanidade, nesse período, pelos países ricos: a estratosférica quantia de 47 trilhões de dólares, ao serem computados "os custos ambientais de atividades humanas ligadas à mudança climática, destruição da camada de ozônio, expansão da agricultura, desmatamento, pesca predatória e danos a mangues" ${ }^{11}$.

Portanto, ao abordarmos essa questão em escala planetária, o que se deve buscar, em primeiro lugar, é a compatibilização urgente, urgentíssima, da diminuição drástica de emissão de $\mathrm{CO} 2$ e outros GEE para a atmosfera, com o direito e a necessidade dos países pobres se desenvolverem e atenderem os direitos e necessidades fundamentais de seus povos.

Entretanto, como atender tais necessidades sem tocar no padrão de vida e consumo das classes médias e altas tanto no Hemisfério Norte, onde são majoritárias, como no Hemisfério Sul, onde são minoritárias? Afinal, já gastamos $25 \%$ a mais do capital natural da Terra e seria preciso que tivéssemos pelo menos quatro planetas Terra para que todos alcancem o perfil do chamado American way of life.

Uma nova 'utopia'12 seria possível na atual configuração geopolítica mundial, onde o poder destrutivo da indústria armamentista, petrolífera e minerária se materializa em governos como de Bush, senhor das guerras no mundo? É possível superar a atual crise nos marcos do sistema capitalista?

São essas questões que, se por um lado, estão postas para a humanidade como um todo, por outro, nos compelem a compreender o papel do Brasil quarto ou quinto maior emissor de GEE e detentor da maior floresta tropical do planeta - nesse enfrentamento. De que forma o país contribui e é impactado

${ }^{10}$ GARCIA, RAFAEL. Jornal Folha de São Paulo, São Paulo, 22.01.2008, Ambiente.

Disponível em: http://www1.folha.uol.com.br/folha/ambiente/ult10007u365782.shtml.

${ }^{11}$ Idem.

${ }^{12}$ Caracterizada pela sustentabilidade ambiental, igualdade social e desenvolvimento econômico em escala planetária. 
pelo aquecimento global? Quais as políticas de desenvolvimento, meio ambiente e de mudanças climáticas do governo brasileiro? São as questões que pretendemos tratar a seguir.

\section{O BRASIL E AS MUdANÇAS CLIMÁTICAS: CONTRIBUIÇÃO E IMPACTOS}

O Brasil, que ainda não tem um plano nacional voltado para a questão das mudanças climáticas, é, atualmente, o quarto (ou quinto, nas novas projeções) maior emissor de GEE do planeta (com 2,5 a $3 \%$ das emissões mundiais). Segundo o Inventário Nacional de Emissão de Gases do Efeito Estufa ${ }^{13}, 75,4$ \% dessas emissões decorrem das mudanças do uso do solo (aqui incluídas a conversão de áreas florestais para pecuária e agricultura mediante queimadas e desmatamento); $22,5 \%$ advêm da queima de combustíveis fósseis; $1,6 \%$ da produção industrial e $0,5 \%$ da extração de carvão, petróleo e gás natural.

Esses dados que, por si só, já são preocupantes, para não dizer vexatórios são do primeiro e único inventário já publicado, que, apesar de ter sido divulgado em 2004, é composto de dados colhidos entre1990 e 1994. De lá para cá, segundo indicadores preliminares que vão integrar o próximo inventário, a situação só fez piorar, com um acréscimo de 45\% na emissão de GEE, entre 1994 e 2005, segundo estudo elaborado pela Economia \& Energia, contratada pelo Ministério da Ciência e Tecnologia (Angelo, 2007).

Conforme o estudo, a emissão do setor de geração de energia cresceu de 7,6 milhões de toneladas de carbono, em 1994, para 15,2 milhões, em 2005. Em transporte, as emissões passaram no mesmo período de 25,4 milhões para 36,9 milhões de toneladas de carbono (ANGELO, 2007).

De acordo com Carlos $\mathrm{Feu}^{14}$, diretor da Economia \& Energia, dois fatores responderam pela elevação das emissões: o brasileiro está andando mais de carro e consumindo energia mais suja.

"No primeiro inventário, quase não existiam usinas termelétricas no Brasil. Agora existem e continuarão existindo". ${ }^{15}$ Ainda segundo Angelo (2007), a matriz energética nacional, antes predominantemente hidrelétrica (cujas emissões não são contabilizadas por falta de critério científico), passou a contar a partir desta década com usinas movidas a combustíveis fósseis como gás natural, diesel e carvão mineral.

${ }^{13}$ BRASIL. Ministério da Ciência e Tecnologia. Inventário Nacional de Emissão de Gases do Efeito Estufa, 2004. Disponível em http://www.mct.gov.br/index.php/content/view/57270.html

${ }^{14}$ APUD ÂNGELO (2007).

15 ÂNGELO, Cláudio. Emissão cresce mais que PIB em São Paulo. In.: Folha de São Paulo. São Paulo, 19.11.2007. Caderno de Ciência.

Disponível em: http://www1.folha.uol.com.br/fsp/ciencia/fe1911200701.htm 
Para se ter uma idéia do impacto atual e futuro, ainda conforme a reportagem de Ângelo (2007):

\begin{abstract}
"o governo federal já dá como fato consumado que o crescimento futuro do país demandará mais energia fóssil. O Plano Nacional de Energia, elaborado pela EPE (Empresa Brasileira de Pesquisas Energéticas), prevê que a participação do gás na matriz nacional em 2030 terá quase dobrado em relação a 2005. A capacidade instalada de usinas a carvão deve quadruplicar no período, de 1.400 para 6.000 megawatts. As estimativas foram feitas antes da confirmação do potencial do campo de petróleo de Tupi, na bacia de Santos - que tende a tornar o óleo uma fonte de energia ainda mais importante no país".
\end{abstract}

A aposta no carvão como combustível para as térmicas é um retrocesso de repercussões gravíssimas para o clima no Brasil e no planeta. Se levarmos em conta que o carvão contribuiu, em 2002, com $41 \%$ da emissão de CO2 para a atmosfera e que, nos cálculos de Tim Flannery (2007), "sem contar às impurezas que contém, várias das quais (como o enxofre e o mercúrio) são poderosos poluidores, o melhor carvão negro é quase puro carbono. Queime uma tonelada dele e você cria 3,7 toneladas de CO2", podemos visualizar um cenário sombrio com a ampliação dessa matriz suja em nosso país (p. 96-97).

O mais grave é que o aumento da liberação de $\mathrm{CO} 2$ não significou um crescimento da renda e da riqueza nacional. "Nesse período, a média de crescimento anual da produção de gases-estufa excluindo o desmatamento foi de $3,4 \%$, enquanto o PIB (Produto Interno Bruto) cresceu 2,6\%. Ou seja, o país está poluindo mais do que gerando riqueza" (ANGELo, 2007).

É nesse quadro de crescimento nacional na emissão de GEE, quando em todo o mundo se busca caminhar no que o Greenpeace denomina de "trilha da descarbonização", que se projetam os cenários mais sombrios para não dizer catastróficos dos impactos de um acréscimo de mais de $2^{\circ} \mathrm{C}$ na temperatura média da Terra sobre os biomas e regiões brasileiras.

O cientista José A. Marengo (2006, p. 136-137), pesquisador-doutor do Instituto Nacional de Pesquisas Espaciais (INPE), com vários trabalhos publicados na área de climatologia, em estudo recente, projetou quais seriam os impactos das mudanças climáticas no Brasil, que transcrevemos a seguir:

“Amazônia - Se o avanço da fronteira agrícola e da indústria madeireira for mantido nos níveis atuais, a cobertura florestal poderá diminuir dos atuais 5,3 milhões de $\mathrm{km}^{2}$ (85\% da área original) para 3,2 milhões de $\mathrm{km}^{2}$ em 2050 (53\% da cobertura original). O aquecimento global vai aumentar as temperaturas na região amazônica, e pode deixar o clima mais seco, provocando a savanização da floresta. $\mathrm{O}$ aquecimento observado pode chegar até $8^{\circ} \mathrm{C}$ no cenário pessimista $\mathrm{A} 2$. 
Os níveis dos rios podem ter quedas importantes e a secura do ar pode aumentar o risco de incêndios florestais;

Semi-árido - As temperaturas podem aumentar de $2^{\circ} \mathrm{C}$ a $5^{\circ} \mathrm{C}$ no Nordeste até o final do século XXI. A Caatinga será substituída por uma vegetação mais árida. $\mathrm{O}$ desmatamento da Amazônia pode deixar o semi-árido mais seco. Com o aquecimento a evaporação aumenta e a disponibilidade hídrica diminui. O clima mais quente e seco poderia levar a população a migrar para as grandes cidades da região ou para outras regiões, gerando ondas de "refugiados ambientais";

Zona Costeira - O aumento do nível do mar vai trazer grandes prejuízos ao litoral. Construções à beira-mar poderão desaparecer, portos poderão ser destruídos e populações teriam que ser remanejadas. Sistemas precários de esgoto entrarão em colapso. Novos furacões poderão atingir a costa do Brasil;

Sudeste e bacia do Prata - Ainda que a chuva tendesse a aumentar no futuro, as elevadas temperaturas do ar simuladas pelos modelos poderiam, de alguma forma, comprometer a disponibilidade de água para agricultura, consumo ou geração de energia devido a um acréscimo previsto na evaporação ou evapotranspiração. A extensão de uma estação seca em algumas regiões do Brasil poderia afetar o balanço hidrológico regional, e assim comprometer atividades humanas, ainda que haja alguma previsão de aumento de chuva no futuro;

Região Sul - A produção de grãos poderá ficar inviabilizada na região Sul do Brasil com o aumento da temperatura, secas mais freqüentes e chuvas restritas a eventos extremos de curta duração. As chuvas cada vez mais intensas poderiam castigar as cidades, com grande impacto social nos bairros mais pobres. Ventos intensos de curta duração poderiam também afetar o litoral. Com temperaturas mais altas e extremas em curto espaço, mais doenças seriam registradas;

Agricultura - Culturas perenes, como a laranja, tendem a procurar regiões com temperaturas máximas mais amenas e a produção poderá se deslocar para o Sul. Elevadas temperaturas de verão vão condicionar o deslocamento das culturas como arroz, feijão, soja para a região Centro-Oeste, promovendo a mudança do atual eixo de produção;

Recursos hídricos - A redução de chuvas e a diminuição da vazão nos rios vão limitar os esgotos e o transporte fluvial. Poderá haver transbordamento de estações de tratamento e de sistemas de sanitário. A geração de energia ficará comprometida com a falta de chuvas e altas taxas de evaporação devido ao aquecimento, em algumas regiões; 
Grandes cidades - Regiões metropolitanas ainda mais quentes, com mais inundações, enchentes e desmoronamentos em áreas principalmente nas encostas de morro;

Saúde - Os casos de doenças infecciosas transmissíveis poderão aumentar. A dengue pode se alastrar pelo País. A proliferação tende a aumentar nas áreas urbanas". (MARENGO, 2006, p. 136-137

Aliás, estudos mais recentes, como o do cientista Daniel Nepstad ${ }^{16}$, trazem um cenário ainda mais aterrador: a transformação da floresta em savana num prazo ainda menor, onde, até 2030, perderíamos metade da mata amazônica para os desmatamentos, as queimadas e as secas.

Vejamos, portanto, como se explica a importância do bioma e da floresta no debate acerca das mudanças climáticas. Compreender o significado da preservação da maior floresta tropical do planeta é fundamental no combate ao aquecimento global. É o que vamos abordar a seguir.

\title{
3 A AMAZÔNIA NO CENTRO DO AQUECIMENTO GLOBAL: SUMIDOURO E EMISSOR DE CARBONO
}

Inicialmente, se faz preciso delimitar o conceito de Amazônia, já que ele comporta vários significados. Não é o conceito geográfico ou legal das regiões brasileiras que vai nos interessar, mas sim o ecológico. Portanto, seguindo a classificação do Almanaque Brasil Socioambiental $2008^{17}$ vamos estar mais voltados para o bioma e sua floresta, que assim são definidos:

\begin{abstract}
"Bioma Amazônia (com 5 milhões de $\mathrm{km}^{2}$, dos quais 4,2 milhões só no Brasil) corresponde ao conjunto de ecossistemas (além da floresta, mangues, cerrados, várzeas etc.) que formam a Bacia Amazônica (...) presente em nove países da América do Sul (...) No Brasil, o núcleo central de sua paisagem, a hiléia (ou floresta) amazônica, com grande concentração de árvores de grande porte, com até 50 metros de altura, tendo o rio Amazonas (o maior do mundo,com $6.850 \mathrm{~km}$ ) como eixo que domina 300 quilômetros para cada lado do seu curso, ocupa 3,5 milhões de hectares" (RiCARDO e CAMPANILI, p. 100).
\end{abstract}

\footnotetext{
${ }^{16}$ NePstad, Daniel. Os ciclos viciosos da Amazônia: estiagem e queimadas na floresta estufa. WWF Internacional, Gland/Switzerland, 2007, 24 p.

Disponível em: http://assets.wwf.org.br/downloads/amazonas_27_11_web.pdf

${ }^{17}$ Ricardo, Beto e Campanili, Maura (Organização). Instituto Socioambiental Almanaque Brasil Sócioambiental. Editora Instituto Socioambiental: 2007
} 
Ali, tudo é superlativo. Estima-se que, na Amazônia, habitem mais de um terço de todas as espécies do planeta a maior biodiversidade da Terra (para se ter uma idéia, o número de espécies de peixes catalogadas na Amazônia, mais de 2.000 , é mais de que 10 vezes maior que todo o continente europeu) -, um terço de toda a madeira tropical, $12 \%$ a $18 \%$ de toda a água superficial doce que desemboca nos mares, 170 povos indígenas, com mais de 180 mil indivíduos (RICARDO e CAmPANILI, p.84 e revista AmazôNiA ${ }^{18}$ Ainda é possível salvar? p. 30).

Do ponto de vista do regime das chuvas em toda a América do Sul, a liberação de 7 trilhões de toneladas de água para a atmosfera, através da evapotranspiração, faz da floresta uma verdadeira "máquina de fazer chuva", na feliz expressão de Herton Escobar, um dos autores da excelente reportagem especial do Estado de São Paulo já referida. Ali, o meteorologista Gilvan Sampaio, do INPE, afirma: "quando você toma um copo d'água em São Paulo, está bebendo água da Amazônia também". O que leva à advertência do também pesquisador do INPE, Antonio Nobre, de que se "você tira floresta, o continente inteiro pode virar uma savana" (AMAZÔNIA Ainda é possível salvar? p. 37).

Quando o tema é seqüestro de carbono, não há consenso científico acerca da capacidade que a floresta tem de retirar o $\mathrm{C}^{2}$ da atmosfera. São encontradas projeções que variam de 250 milhões de toneladas até a impressionante cifra de 1,5 bilhão de toneladas por ano. No entanto, é fato que ali se encontra um dos maiores e expressivos depósitos de carbono de todo o planeta. O professor Carlos Nobre (2002), do INPE e membro brasileiro do IPCC, afirma que a Amazônia "armazena mais de cem gigatoneladas de carbono em vegetação e solos"19.

Essa variação é reconhecida por Carlos Nobre (2002) quando faz uma projeção da capacidade de absorção do dióxido de carbono por parte de nossa floresta e afirma, no mesmo artigo:

(...) "estudos sobre os ciclos do carbono do Experimento BiosferaAtmosfera em Larga Escala (LBA em inglês) e os estudos de inventário florestal (Phillips et al., 1998) indicam que a floresta intacta pode ser um absorvedouro de carbono em taxas que vão de 0,8 até a elevada cifra de 7 toneladas de C/ha-1 anuais (Malhi et al., 1998; Malhi et al., 1999; Araújo et al., 2002; Nobre et al., 2000) “. (apud NoBre, 2002).

$\mathrm{O}$ fato de ser, a um só tempo, sumidouro e emissor de $\mathrm{CO}^{2}$ é quem explica a importância da Amazônia no tratamento do combate aquecimento global no país

${ }^{18}$ O Estado de SÃo Paulo. Revista Amazônia Ainda é possível salvar? O Estado de São Paulo: nov./dez./2007. Ver: http://www.estadao.com.br/amazonia/

${ }^{19}$ NoBre, Carlos. AAmazônia e o carbono atmosférico. In.: Scientific American Brazil, ed. 6, nov. 2002. Disponível em:http://www2.uol.com.br/sciam/reportagens/a_amazonia_e_o_carbono_ atmosferico.html 
e no mundo. Afinal, se ali é encontrada uma centena de gigatoneladas de carbono, são as queimadas e os desmatamentos quem afinal findam por colocar a questão da preservação das florestas e dentre elas, a maior mata tropical do mundo no centro do debate sobre as mudanças climáticas.

Ainda mais, porque, conforme estudo recente do Greenpeace, Mudanças do Clima, Mudanças no Campo: impactos climáticos da agricultura e potencial de mitigação ${ }^{20}$, elaborado pelo professor Pete Smith et AL., da Universidade de Aberdeen e membro do IPCC, a

"agricultura é atualmente uma das mais importantes fontes de emissão de gases do efeito estufa e mudanças urgentes precisam ser feitas no modo como a atividade é exercida para torná-la ambientalmente sustentável"' (Greenpeace, 2008).

Ali, já se estima que a

"contribuição total da agricultura mundial para as mudanças climáticas, incluindo desmatamento para plantações e outros usos, é estimada em algo entre 8,5 bilhões e 16,5 bilhões de toneladas de dióxido de carbono, ou entre $17 \%$ e $32 \%$ de todas as emissões de gases do efeito estufa provocadas pelo ser humano" (CORDEIRO, 2008, p.2).

Certamente, grande parte dessa contribuição adveio dos mais de 700 mil quilômetros quadrados de floresta destruidos em cinco décadas o que corresponde

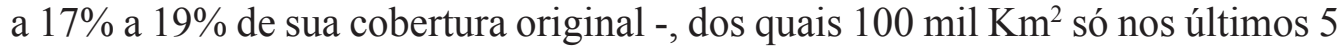
anos, uma área maior do que Portugal. Segundo Herton Escobar, "pesquisadores do Instituto do Homem e do Meio Ambiente da Amazônia (IMAZON), em Belém, estimam que só $43 \%$ do bioma permanece verdadeiramente intacto, livre de ocupação e da influência de atividades humanas sejam elas legais ou ilegais" (AMAZÔNIA Ainda é possível salvar? p. 45).

Demonstrada a importância da Floresta Amazônica para o equilíbrio do clima no planeta, é que iremos, a seguir, procurar compreender como vem se dando a ocupação predatória daquela região, analisando não só a ação da mão pesada e nada invisível - do mercado, mas também do Estado que, por omissão, ação ou incentivo, tem grande responsabilidade nesse processo.

20 Smith, Pete et Al., GreenPeAce, 2008. Mudanças do Clima, Mudanças no Campo: impactos climáticos da agricultura e potencial de mitigação. Greenpeace Internacional: 2008. Disponível em: www. greenpeace.org/brasil/greenpeace-brasil-clima/noticias/mudan-asado-clima-mudan-as-no 


\section{O Estado E O CAPITAL, DE MÃos DADAS, QUASE SEMPRE, NO ATAQUE À FLORESTA}

É de todos conhecido que o processo de ocupação massiva da Amazônia se dá, principalmente, nos governos militares (1964-1985), que, embalados pela ideologia da segurança nacional comum a todas as ditaduras do continente sulamericano à época, pregavam a ocupação da floresta, sob o lema "integrar para não entregar". Afinal, até o começo dos anos 70 , só $1 \%$ da floresta havia sido destruído; em meados de 1998, ele alcança quase 14\% (uma área do tamanho da França), estando, hoje, como já dito, em mais de $17 \%$ a área de mata devastada.

É a partir daquela época, que se gestam e se executam os grandes programas de infraestrutura ${ }^{21}$ ao lado da política de incentivos fiscais - levada a cabo pela Superintendência de Desenvolvimento da Amazônia (SUDAM) e pelo Banco da Amazônia (BASA) que financiaram projetos agropecuários insustentáveis na região (para não falar na corrupção), até a política de colonização voltada aos pequenos agricultores, que desbravam a mata para a chegada, posterior, de madeireiros, sojeiros e pecuaristas.

Um capítulo à parte seria o estudo dos impactos da mineração e da produção de ferro-gusa para a siderurgia, a partir do uso do carvão vegetal. Para se ter uma idéia do impacto dessa atividade, calcula-se que, em 2006, dos mais de 35 milhões de metros cúbicos de carvão vegetal consumidos no país, 49\% (mais de 17 milhões de metros cúbicos) foram obtidos a partir de matas nativas. É no Pará que se encontra a maior jazida de ferro do mundo, no pólo siderúrgico de Carajás.

Já em 1999, o Greenpeace, em sua publicação "Face a Face com a Destruição: Relatório Greenpeace sobre as Companhias Multinacionais Madeireiras na Amazônia Brasileira", alertava:

\footnotetext{
"a participação da madeira amazônica no total da produção brasileira pulou de $14 \%$ para $85 \%$ em apenas duas décadas; dos 36 pontos críticos de desmatamento na Amazônia, 72\% estão relacionados à indústria madeireira; $80 \%$ da madeira explorada na Amazônia têm origem ilegal”. (Cotta e Romine. Greenpeace Brasil, 1999. p. 2)
}

Ali já se constatava que "a construção de estradas e o desflorestamento realizado por fazendeiros para fins agropecuários são financiados pela venda de madeira tropical destas áreas" (VerísSimo ET AL, 1995, APUd CotTA E Romine. GreenPeace Brasil, 1999. p. 6).

${ }^{21}$ Como a rodovia Transamazônica e as grandes hidrelétricas, como a de Balbina, responsável por um dos maiores desastres ambientais da região. 
Aliás, essa situação só fez se agravar nos últimos cinco anos do Governo do Presidente Lula. Segundo estudo ${ }^{22}$, houve um deslocamento da criação de gado do Centro Oeste para a Amazônia Legal, de forma bastante intensa. Na Amazônia, se encontra, hoje, $94 \%$ do crescimento do número de cabeças registrado no país entre 2003 e 2006. Das 10.334.668 novas cabeças de gado registradas no Brasil pelo IBGE, no período considerado, 9.680.511 estavam na Amazônia Legal (SMERAldi e May, 2008)

O estudo teve uma ampla repercussão em um dos principais veículos da imprensa brasileira, o jornal Folha de São Paulo, que estampou, em sua edição de 13 de janeiro deste ano, a manchete: "Com estímulo oficial, floresta vira capim" (p. A31). Ali, se noticia que o rebanho bovino na Amazônia cresceu de 35 milhões de cabeça em 1994 para quase 74 milhões em 2006.

É uma destruição subsidiada pelos bancos e fundos públicos. A reportagem citada, de Marta Salomon, noticia que:

\begin{abstract}
“a expansão da pecuária de corte na região conta com duas linhas de financiamento operadas pelo Banco da Amazônia, com juros subsidiados, entre $0,5 \%$ e $10,5 \%$ ao ano - os mais baratos do país. De micro a grandes, os pecuaristas só em um dos estados da região (o Pará) receberam R\$ 80 milhões em empréstimos em 2007 do Pronaf (Programa Nacional de Agricultura Familiar) e do FNO (Fundo Constitucional do Nordeste)" (SAlomon, 2008, p. A31).
\end{abstract}

Além disso, essa ocupação é facilitada pelo caos fundiário, que torna as terras públicas, ocupadas de forma ilegal, extremamente baratas, e pela ausência dos órgãos de poder estatal, seja na área ambiental, fundiária ou até mesmo policial, dado o grande número de conflitos pela posse da terra na região, o que torna o Estado do Pará o campeão em violência e mortes de trabalhadores rurais no país. Para se ter uma idéia, segundo a Comissão Parlamentar Mista de Inquérito que investigou a situação fundiária do país (CPI da Terra), de 42 mortes no campo em 2003, 19 ocorreram no Pará (Melo, 2006).

Mas, não é só a pecuária. Também a soja passou a ser um dos vetores do desmatamento na região. Entre os anos de 2004 e 2005, incentivados pela instalação ilegal de um porto fluvial em Santarém, no Estado do Pará, pela gigante multinacional Cargill (que, ao lado, da ADM e da Bunge, controlam 60\% das exportações de soja proveniente do Brasil), foram plantados no Bioma Amazônia algo em torno de 1,2 milhões de hectares de soja, o que corresponde a 5\% do plantio nacional (GreEnPEACE InTERnacional, Holanda 2006).

22 "O Reino do Gado. Uma nova fase na pecuarização da Amazônia" é o estudo realizado por Roberto Smeraldi e Peter H. May, da ONG Amigos da Terra - Amazônia Brasileira. Disponível em: http://www.amazonia.org.br/arquivos/259381.pdf 
Abram-se, aqui, parêntesis para aduzir que, em face da campanha lançada pelo Greenpeace em toda a Europa, a partir das redes de fast food, como a McDonald's (principais consumidoras da soja produzida na região), a Associação Brasileira da Indústria de Óleos Vegetais (ABIOVE) e a Associação Nacional dos Exportadores de Cereais (ANEC) e suas associadas anunciaram, em julho de 2006, uma moratória de dois anos para a compra de soja proveniente de novas áreas desmatadas na Amazônia, além da exclusão de fazendas que usam mão-deobra escrava, a partir de então. Experiência que está em pleno andamento, com o acompanhamento de ongs ambientalistas, que passa por fase crítica e decisiva, qual seja, a capacidade de monitorar as áreas desmatadas e a credibilidade das traders, em teste no que concerne à aquisição da soja plantada na região.

Até programas sociais importantes, como a reforma agrária, em sua versão ambientalmente correta como os chamados PDS (Planos de Desenvolvimento Sustentável), criação da religiosa católica Dorothy Stang, assassinada, no Pará, em 2005 - são desvirtuados para atender aos interesses criminosos das grandes madeireiras. Estudo do Greenpeace, intitulado "Assentamentos de Papel, Madeira de Lei ${ }^{23}$ " denunciou, em agosto do ano passado, um conluio entre governo, através do Instituto Nacional de Colonização e Reforma Agrária (o INCRA), e as empresas madeireiras da região, para esquentar a madeira ilegal e inflar artificialmente o número de assentados pelo programa de assentamentos de trabalhadores rurais sem terra (GREENPEACE, 2007).

Para contornar a exigência da Portaria 10/2004, do Ministério do Desenvolvimento Agrário (MDA) e do próprio INCRA, que exigia o título de propriedade para a liberação de planos de manejo de extração de madeira, acertou-se a criação massiva muitas vezes artificial e até virtual (pois sem trabalhadores efetivamente assentados) - de assentamentos, na região de Santarém/Pará um total de quase 100 em uma área de 30 mil quilômetros quadrados - para serem usados como área regularizada em termos fundiários para atender aos madeireiros (GREENPEACE, 2007).

Nas palavras de Mauricio Torres, o

“madeireiro passou então a ser o 'cliente da reforma agrária'. O Incra criou assentamentos em áreas com estoques ainda intocados de madeiras nobres, ou seja, nas distantes florestas primárias ainda não saqueadas. Porém, justamente essa condição elimina qualquer chance de famílias se instalarem no local" (apud MST, 2007).

${ }^{23}$ Disponível em: http://www.greenpeace.org/raw/content/brasil/documentos/amazonia/ greenpeacebr_070821_amazonia_relatorio_assentamentos_incra_port_v2.pdf 
Segundo o relatório do Greenpeace $(2007$, p. 3) "as empresas chegaram, inclusive, a determinar onde os assentamentos deveriam ser criados, escolhendo as áreas com mais disponibilidade de madeira de valor comercial".

Para barrar o que o geógrafo e professor da Universidade de São Paulo, Ariovaldo Umbelino chamou de "uso criminoso da reforma agrária", o Ministério Público Federal do Pará solicitou e a Justiça mandou interditar os 99 assentamentos criados ilegalmente na região (In.: Carta Capital, de 31 de outubro de 2007).

O caso acima é um dos mais emblemáticos da política contraditória e insustentável do governo brasileiro para a região, seu bioma, seu povo e sua floresta. O atual governo apresenta indicadores conflitantes: entre agosto de 2003 e agosto de 2004 (nos dois primeiros anos do primeiro governo), foi registrado o segundo maior índice anual de desmatamento da floresta amazônica, em toda a sua história: $26.130 \mathrm{~km}^{2}$. Por outro lado, houve uma redução de aproximadamente $50 \%$ desde então até meados do ano passado; se verificando, no momento, um recrudescimento do desflorestamento a partir do segundo semestre do ano passado. É essa política contraditória que pretendemos relatar a seguir.

\section{F GOVERNO LULA: DESENVOLVIMENTISMO INSUSTENTÁVEL VERSUS RESISTÊNCIA AMBIENTALISTA (ENXUGANDO GELO EM TEMPOS DE AQUECIMENTO GLOBAL)}

No momento em que se escreve este $\operatorname{artigo~}^{24}$, os jornais brasileiros estampam em suas manchetes: "Desmatamento na Amazônia dispara e põe governo em alerta. Foram derrubados $3.223 \mathrm{~km}^{2}$ de floresta de agosto a dezembro: total pode chegar a $15 \mathrm{mil} \mathrm{km} \mathrm{km}^{2}$ em doze meses" ${ }^{25}$. A notícia vem em pior hora para o Governo, que vinha comemorando, desde o ano passado, a redução, pelo terceiro ano seguido, do índice de desmatamento, pois este havia chegado a um dos menores números embora ainda extremamente elevado desde que se começou a medição por satélite: $11.224 \mathrm{~km}^{2}$, para o período 2006/2007 (Domingos E Francisco, 2008).

O alerta já vinha sendo feito desde meados do segundo semestre de 2007. No dia 23 de setembro, o jornal "O Globo", em matéria escrita por Rodrigo Taves (2007), estampava: "Devastação da Amazônia volta a crescer: queimadas em áreas de floresta sobem $30 \%$ este ano em relação a 2006 e serrarias operam a todo vapor". Em 16 de outubro, era a vez do "Estado de São Paulo" denunciar, a partir de dados do Sistema de Alerta do Desmatamento (SAD), operado pelas

${ }^{24}$ Artigo escrito no final de janeiro de 2008.

25 Domingos, João e Francisco, Nelson. Desmatamento na Amazônia dispara e põe governo em alerta. Foram derrubados $3.223 \mathrm{~km}^{2}$ de floresta de agosto a dezembro: total pode chegar a 15 mil km² em doze meses. Jornal O Estado de São Paulo, São Paulo, 24.01.2008, Caderno Vida \&. Disponível em: http://www.estado.com.br/editorias/2008/01/24/ger-1.93.7.20080124.13.1.xml 
ongs Imazon e ICV: "Desmatamento volta a crescer e faz governo rever plano para Amazônia". Ali, se informa que a devastação no estado de Mato Grosso (ao lado do Pará e de Rondônia, os campeões de desflorestamento), "saltou 107\% na comparação de junho/setembro com mesmo período de 2006" (АMORIM, 2007).

A própria Ministra do Meio Ambiente, Marina Silva, segundo reportagem reconheceu que "já é possível dizer que o aumento do preço da soja, o avanço do gado na Amazônia e a derrubada de árvores para as siderúrgicas de ferro-gusa são as causas principais do desmatamento. Seus assessores lembraram que a derrubada da floresta aconteceu principalmente em Mato Grosso, Rondônia e no Pará, Estados onde esses setores da economia têm avançado muito nos últimos anos" (Domingos e Francisco, 2008).

A questão da variação do preço das commodities agrícolas já vinha sendo apontada pelas ongs como uma das causas embora o governo à época não quisesse admitir da queda do desmatamento a partir de agosto de 2004 (após o pico de $26.130 \mathrm{~km}^{2}$, verificado entre agosto de 2003 e agosto de 2004). Na publicação "Faltou Ação ao Plano de Ação", o Greenpeace apontava, dentre os fatores que tinham contribuído para a queda dos índices o "momento desfavorável para as commodities agrícolas brasileiras no mercado internacional. O otimismo dos produtores que estimulou o forte desmatamento do período 2003/2204 foi abalado pela redução dos preços da soja e pela sobrevalorização do Real em relação ao dólar. O faturamento do setor de grãos em geral no país US 47 bilhões na safra 2004/2005 caiu US\$ 13 bilhões em relação à safra anterior" (MARQuesini ET AL, GREenPEACE, 2005, p. 3).

Evidentemente, que não se desconhece, também, que ações do governo contribuíram para a queda que se verificou de 2004 a 2007. Assim, a criação de grandes áreas protegidas - unidades de conservação e homologação de terras indígenas - numa área aproximada de $287 \mathrm{mil} \mathrm{Km}^{2}$; a realização de grandes operações conjuntas do órgão ambiental federal, o Ibama, com a Polícia Federal, que levaram a apreensão de madeira ilegal e à prisão de servidores públicos corruptos, além de madeireiros e lobistas; dentre outras medidas impactantes algumas delas desencadeadas após o assassinato de Ir. Dorothy, em fevereiro de 2005 - devem ser reconhecidas como medidas importantes no combate ao desmate, à grilagem (aquisição ilegal de terras públicas) e à violência na região amazônica.

No entanto, a retomada vigorosa do desflorestamento mostra que nem a presença de Marina Silva no comando da pasta do Meio Ambiente do governo brasileiro é suficiente para dar conta do desafio que é uma política efetiva para a questão do combate ao aquecimento global. Símbolo da luta ambiental, a ponto de, recentemente, ter sido citada pelo jornal britânico The Guardian como uma das 50 personalidades que podem ajudar a salvar o planeta, Marina que tem uma histórica política e pessoal de superação emblemática é herdeira de outro ícone da luta socioambiental brasileira, o seringueiro, como ela, Chico Mendes, assassinado, no século passado, por sua luta em defesa da floresta. 
A questão é outra. Ou, para usar um conceito que a própria Ministra gosta de utilizar, falta "transversalidade ambiental" nas ações de governo voltadas para o binômio meio ambiente/desenvolvimento, vis a vis a questão das mudanças climáticas. Basta que se diga que enquanto Marina responsabilizava o gado e a soja pela devastação, outro ministro do governo Lula, Reinold Stephanes, da Agricultura, fazia a defesa enfática do agronegócio. Abram-se, aqui, parêntesis para aludir que esse integrante do governo defende o plantio de cana para o etanol na Amazônia e sua pasta é responsável por todas as políticas do setor que tem sido responsabilizado pela degradação da floresta (em outro enfrentamento com o titular anterior da mesma pasta de agricultura, Roberto Rodrigues, Marina foi derrotada com a introdução das plantas transgênicas no país).

A aliança social e política celebrada pelo governo com o agronegócio, que tem, no parlamento brasileiro, como seu representante, a bancada ruralista, é fundamental para o modelo econômico adotado e para a chamada "governabilidade". Na economia, a exportação de produtos oriundos da agricultura e da pecuária tem um peso importante para o equilíbrio da balança comercial. No Congresso, a presença na base de sustentação do governo confere à bancada ruralista posição privilegiada na concessão de favores, privilégios quase sempre traduzidos, além de cargos na estrutura de governo, em generosos abatimentos em suas dívidas agrícolas junto às instituições financeiras oficiais para garantir a aprovação de matérias legislativa de interesse do Executivo.

É essa aliança que, com um falso discurso "verde", incentiva a monocultura da cana-de-açúcar para a produção do etanol combustível, que se tem mostrado insustentável, tanto do ponto de vista social pela superexploração dos cortadores de cana e pela substituição de culturas de subsistência como ambiental, já que sua expansão, além de empurrar a soja e o gado ainda mais para dentro da floresta, é responsável pela degradação de outro grande bioma brasileiro, o Cerrado, que é a savana com maior biodiversidade do planeta.

Estudo do Instituto Sociedade, População e Natureza (ISPN) ${ }^{26}$, concluiu que:

“importantes áreas para a conservação e uso sustentável da biodiversidade do Cerrado que deveriam ser protegidas estão sendo tomadas pelas lavouras de cana-de-açúcar para produção de etanol. Isso significa que pode haver comprometimento dos recursos naturais, das populações rurais e da segurança alimentar na região”. (p. 1)

${ }^{26}$ Instituto Sociedade, População e Natureza. ISPN. Cana de Açúcar avança em áreas prioritárias para conservação e uso sustentável do cerrado. Disponível em: http://www.ispn.org.br/ LevantamentoSite.pdf 
Ali, se denuncia que o Cerrado, que abrange cerca de dois milhões de quilômetros quadrados já perdeu metade de sua cobertura vegetal, estando as causas do desmatamento "relacionadas à agricultura e pecuária praticadas inclusive sobre áreas que deveriam estar sob proteção e que são a base do estudo do ISPN". Segundo Nilo Dávila, assessor de políticas públicas da entidade, "apesar de não haver monitoramento oficial, estima-se que o desmatamento na região gire em torno de $1,1 \%$ ao ano, o equivale à destruição de cerca de $22 \mathrm{mil} \mathrm{km}^{2}$ por ano, sendo maior que o desmate na Amazônia" (ISPN, p. 1).

É essa sólida aliança governo Lula com o capital agropastoril que explica o fato de que, um dos maiores beneficiários do chamado Plano de Aceleração do Crescimento $^{27}$, na atilada análise de Gerson Teixeira (2007) seja “o agronegócio exportador, em particular, na sua trajetória expansiva na fronteira Norte" (p. 7). Ali, Teixeira constata que, para

"pavimentar, de vez, a expansão do agronegócio na Amazônia, o PAC prevê investimentos de peso no binômio 'energia e asfalto', afora em hidrovias, que, entre outros efeitos, romperão as principais barreiras para essa atividade naquela região e da sua transformação em via de acesso a mercados internacionais de produtos de outras regiões" (p. 7).

Ou seja, o mesmo governo que anuncia medidas duras de combate ao desflorestamento, como o recente Decreto 6321/200728, realiza pesados investimentos públicos em infraestrutura (rodovias, hidrovias, energia) que poderão fazer da Amazônia, segundo ainda a percuciente análise de Teixeira, não apenas a grande fronteira da energia elétrica, mas, também, "a última fronteira do agronegócio brasileiro" (TEIXEIRA, 2007, P. 8).

Além desses impactos sobre a fauna e a flora, o próprio governo reconhece, segundo informações do Conselho Indigenista Missionário, que 201 empreendimentos do PAC interferem em terras indígenas, dessas $21 \mathrm{com}$ povos isolados. Dentre essas obras, se encontram as barragens de Santo Antônio e Jirau, no rio Madeira (RO), que vai impactar grupos de índios isolados que vivem na região; a hidrelétrica de Belo Monte, no rio Xingu (PA), que atinge terras dos povos Arara, Xincrin e Juruna; a hidrelétrica de Estreito, no rio Tocantins, que traz impactos sobre as terras indígenas Avá Canoeiro, Kraolândia, Funil, Xerente, Apinayé, Krikati e Mãe Maria; a BR-156 no Amapá, que corta 40 km de terra dos povos Galibi-Marworno, Palikur e Karipuna; a BR 242, no Tocantins , que atinge os povos da Ilha do Bananal: Avá Canoeiro, Javaé, Karajé e Cara Preta.

${ }^{27}$ Conjunto de ações, políticas, empreendimentos, que formam o carro-chefe da política desenvolvimentista do governo brasileiro.

${ }^{28}$ Decreto n. 6321, de 21 de dezembro de 2007. Dispõe sobre ações relativas à prevenção, monitoramento e controle do desmatamento no Bioma Amazônia. 
Em nenhum momento, até agora, houve qualquer consulta prévia a esses povos, o que denota o profundo desrespeito com o direito dos povos indígenas.

A comprovação maior de que não há política ambiental integrada transversalmente com os outros setores do governo é, exatamente, esse Plano de Aceleração de Crescimento, que, efetivamente, é o nome do projeto de desenvolvimento para o segundo mandato do Presidente Lula. Ali, estão previstas, além do que acima foi listado, outras ações que atentam contra o meio ambiente e o clima do planeta, tais como a construção de 77 usinas termoelétricas (a maioria a carvão e a óleo), a retomada do programa nuclear brasileiro, a transposição do Rio São Francisco, a construção das já referidas usinas hidrelétricas do Rio Madeira (cujo parecer inicial do órgão de meio ambiente era contrário, pelos impactos socioambientais causados), o incentivo à siderurgia (com a desoneração do Impostos sobre Produtos Industrializados (IPI) para o aço) etc.

Portanto, a insustentabilidade da política de desenvolvimento do governo brasileiro não se encontra somente na Amazônia onde o PAC, na contramão das ações do Ministério do Meio Ambiente, incentiva a continuidade do desmate da floresta mas, também, nos outros setores energia, indústria, transportes causadores da emissão de gases do efeito-estufa. De nada adianta a elaboração, por um ou dois ministérios, apenas, de um plano de enfrentamento às mudanças climáticas em seus aspectos de prevenção, mitigação e adaptação se, no centro das políticas públicas levadas a cabo ou estimuladas pelo governo - com investimentos, créditos, incentivos fiscais e subsídios - se encontra a ideologia do crescimento a qualquer custo, onde a economia se sobrepõe ao social e ao ecológico, onde o governo se rende à lógica do mercado, onde as políticas ambientais ainda estão e como estão! à margem dos grandes processos decisórios.

Nesse quadro, vamos, na parte final, ouvir o que tem a dizer e o que estão fazendo os movimentos sociais, ecológicos e socioambientais, dentro da compreensão de que é, no âmbito da sociedade, que germinam as sementes das transformações que se fazem necessárias para o enfrentamento da crise global em que estamos mergulhados, não só em seu aspecto climático, mas, fundamentalmente, no que concerne aos padrões de apropriação, produção e consumo vigentes. Uma crise que, mais do que ser de um modelo, é de fundo civilizacional. Afinal, são os fundamentos do modo de produção capitalista e de seu ethos que são questionados neste momento crucial para o gênero humano.

\section{7 À GUISA DE CONCLUSÃO: UMA VISÃO EM PERSPECTIVA DA LUTA SOCIOAMBIENTAL - AS PROPOSTAS PARA A CRISE E AS NOVAS ALIANÇAS QUE SE TECEM}

Nossa visão de mundo (e creio que ficou claro no decorrer deste artigo) é que a atual crise ambiental global - dada a sua gravidade e extensão, em face do atual sistema político-econômico-cultural dominante, o capitalismo, com sua lógica 
insustentável de apropriação privada dos bens naturais, que a tudo transforma (inclusive os seres vivos) em mercadoria, com sua busca incessante do lucro, através do incentivo ao consumismo sem limites não se resolverá nos marcos desse mesmo sistema. É preciso, portanto, desde já, organizar o que Bellamy Foster já citado, chama de Revolução Ecológica.

No entanto, esse processo está apenas em construção, tanto no que diz respeito ao que se pretende de um novo sistema econômico e de uma nova sociabilidade, que estabeleça uma outra relação com o seu entorno natural não humano, como no que se refere às alianças, às propostas e aos meios de se chegar a esse objetivo.

Portanto, é preciso ficar atento às propostas que se gestam no seio das ongs, e as novas formas de lutas dos movimentos sociais e socioambientais, como ainda nas experiências comunitárias e de povos tradicionais (como índios, quilombolas, ribeirinhos etc.), que, por dentro da própria sociedade capitalista insustentável, constituem novos (às vezes baseadas em vivências ancestrais) modos de vida, de produção e de consumo.

Aqui no país, as grande ongs ambientalistas já têm apresentado uma gama muito importante de reflexão e de propostas para a solução da atual crise. No que concerne à questão das energias renováveis limpas, o WWF ${ }^{29}$, em conjunto com pesquisadores da Universidade de Campinas (UNICAMP) e da Pontifícia Universidade Católica do Rio Grande do Sul (PUC/RS), apresentou a sua "Agenda Elétrica Sustentável 2020: estudo de cenários para um setor elétrico brasileiro eficiente, seguro e competitivo" (WWF-BRAsIL, 2007).

$\mathrm{Na}$ mesma linha, e com a parceria, dentre outros da Universidade de São Paulo (USP) e do Conselho Europeu de Energia Renovável, o Greenpeace fez publicar, agora, no ano de 2007, a sua "(R)evolução Energética: perspectivas para uma energia global sustentável” (GREENPEACE, 2007). Não se pode, portanto, acusar a sociedade civil movimentos, universidades, ongs de se furtar a apresentar soluções, técnica e economicamente viáveis e ambientalmente sustentáveis para a questão energética que nos livre, definitivamente, da matriz suja que o governo insiste em ampliar.

No que tange à problemática crucial da Amazônia, uma aliança de 9 ONGs (Greenpeace; WWF; IPAM Instituto de Pesquisa Ambiental da Amazônia -; ICV Instituo Centro de Vida -; CI Conservação Internacional Brasil -; TNC The Nature Conservancy no Brasil -, Amigos da Terra, IMAZON - Instituto do Homem e Meio Ambiente da Amazônia - e ISA Instituo Sócio Ambiental)

\footnotetext{
29 “O WWF-Brasil é uma organização não governamental brasileira dedicada à conservação da natureza com o objetivo de harmonizar a atividade humana com a conservação da biodiversidade e promover o uso racional dos recursos naturais em benefício dos cidadãos de hoje e das futuras gerações." In.:http:// www.wwf.org.br/wwf_brasil/wwf_brasil/index.cfm
} 
elaborou um alentado e ousado estudo para zerar o desflorestamento em 7 anos, com a adoção de políticas públicas de incentivos, financiamento e de comando e controle, com a criação de mecanismos financeiros, inclusive com a previsão de um fundo público (denominado Fundo Amazônico) para o fortalecimento da gestão florestal e o pagamento por serviços ambientais, com metas quantificáveis ano a ano, que possibilitem "extinguir o desmatamento na Amazônia até 2015, resguardados os usos tradicionais da floresta" ${ }^{30}$ p. 3.

Vale aqui ressaltar que o que o "Pacto pela Valorização da Floresta e pelo Fim do Desmatamento na Amazônia Brasileira" se sustenta, fundamentalmente, na idéia de 'governança florestal' e de incentivos aos 'atores sociais responsáveis pela conservação da floresta (povos indígenas, comunidades locais, populações tradicionais, agricultores familiares)', sem, no entanto, esquecer o chamado setor produtivo, desde que assumam "estratégias de redução de desmatamento e de conservação da floresta" ${ }^{31}$.

Também a Via Campesina ${ }^{32}$ apresentou suas propostas para combater o aquecimento global, a partir da compreensão de que "nenhuma solução tecnológica vai resolver o desastre social e do meio ambiente", pois "somente uma mudança radical na forma como produzimos, comercializamos e consumimos pode dar terras para comunidades rurais e urbanas saudáveis" ${ }^{33}$

Para a Via, que tem uma crítica muito vigorosa à agricultura industrializada, aqui incluído o setor dos agrocombustíveis, a solução para o campo passa, a partir de uma visão agroecológica, pela "agricultura sustentável em pequena escala, um trabalho intensivo e de pouco consumo de energia que podem contribuir para o resfriamento da terra:" ${ }^{34}$.

São essas as sementes do futuro que queremos construir: uma sociedade fundada na sustentabilidade e justiça ambiental, na igualdade social e na democracia política participativa.

Essa relação entre as lutas sociais e ambientais tem uma importância fundamental, não só para os ecossocialistas, mas para o próprio futuro do planeta. Nelas se encontra uma resistência que - partindo da luta concreta por direitos humanos básicos de moradia, cultura, de modo de vida e de produção, e, também,

\footnotetext{
${ }^{30}$ Pacto pela Valorização da Floresta Pelo Fim do Desmatamento da Amazônia. Disponível em: http://www. greenpeace.org/raw/content/brasil/documentos/amazonia/pacto-pela-valoriza-o-da-flor.pdf

${ }^{31}$ Idem nota de rodapé 31.

32 Organização que reúne milhões de camponeses em todo o mundo e da qual fazem parte no Brasil, dentre outros, o Movimento Sem Terra (MST), o Movimento dos Atingidos por Barragens (MAB), o Movimento dos Pequenos Agricultores (MPA), o Movimento das Mulheres Camponesas (MMC), a Comissão Pastoral da Terra (CPT).

${ }^{33}$ MST. Posição da Via Campesina Internacional sobre o Aquecimento Global e os Agrocombustíveis. MST:2007. Disponível em: http://www.mst.org.br/mst/pagina.php?cd=4517

${ }^{34}$ Idem nota de rodapé 34 .
} 
pelo ambiente saudável - questiona os fundamentos não só do atual modelo econômico, mas, em última análise, investe contra as bases do próprio modo de apropriação privada do sistema capitalista, responsável pelo atual estágio de degradação do ambiente planetário. Nessas lutas, bem como nas experiências de comunidades tradicionais, se contrapõem não só interesses materiais, mas formas de vida e de produção antagônicas.

Entendemos, portanto, que, neste momento (mesmo que ainda de forma não articulada) podem se estar forjando não só as alianças sociais fundamentais para esse processo de transformação urgente e necessário - a Revolução Ecológica mas, também, as bases sócio-econômico-ecológico-cultural-ético-políticas de uma nova sociedade que possa superar a atual crise ambiental global para se tornar, a um só tempo, ecologicamente sustentável, socialmente justa e igualitária, cultural e etnicamente diversa, e política e radicalmente democrática: a sociedade ecossocialista. Esse é o desafio que se coloca não só para os ecossocialistas, mas para toda a humanidade. Estaremos à altura dele?

\section{Posfácio: Queda de Marina acentua Contradições}

Este texto já estava pronto, quando a então Ministra Marina Silva apresentou, publicamente, seu pedido de demissão do Ministério do Meio Ambiente. Os episódios de sua queda estavam relacionados tanto com o avanço do Ministro Mangabeira Unger sobre as atribuições do MMA (principalmente no que tange à gestão do Plano Amazônia Sustentável, o PAS, uma espécie de contraparte ao PAC), como na pressão dos governadores, Blairo Maggi à frente, contra as medidas tomadas para obrigar fazendeiros a regularizarem suas terras e restringir o crédito bancário para os desmatadores. Sua saída, como ela mesma disse, foi um gesto carregado de simbolismo para constranger o governo que estava propenso a ceder, ainda mais, aos degradadores.

A entrada de Carlos Minc no Ministério que se apresenta diferenças no estilo midiático de abordar a problemática ambiental em contraposição ao trato discreto da ex-Ministra não altera a essência da política de governo. Aliás, foi isso que o próprio Presidente Lula disse quando falou que a política ambiental (?) não mudaria com a troca dos ministros. Pelo contrário, em pouco tempo de Minc, já tivemos as licenças para a Usina Nuclear Angra III e a aprovação de uma medida provisória que legitima a grilagem na Amazônia (o chamado "PAG: Plano de Aceleração da Grilagem"), para não falar em um avanço ainda maior dos transgênicos, da tentativa de diminuição da reserva legal florestal na Amazônia, da imposição das grandes hidrelétricas naquela região etc.

$\mathrm{Na}$ verdade, vai ficando mais claro que a visão ideológica do governo, sua aliança com o grande capital, seja ele, do setor financeiro, seja da área de infraestrutura ou do agronegócio desvelam ainda mais a insustentabilidade dessas 
políticas, porque enquanto a vela a Deus mingua a olhos vistos, aquela que é acesa para o Diabo tem, infelizmente, sua chama cada vez mais forte. A chama que incendeia e destrói a vida, a megadiversidade, a sociodiversidade que se encontram em nossa grande floresta tropical: a Amazônia.

\section{REFERÊNCIAS}

Amorim, Cristina. Desmatamento volta a crescer e faz governo rever plano para Amazônia. Jornal O Estado de São Paulo, São Paulo, 16.10.2007, Vida \&. In.: http://www.estado.com.br/editorias/2007/10/16/ger-1.93.7.20071016.1.1.xml Ângelo, Cláudio. Emissão cresce mais que PIB em São Paulo. In.: Folha de São Paulo. São Paulo, 19.11.2007. Caderno de Ciência

Disponível em: http://www1.folha.uol.com.br/fsp/ciencia/fe1911200701.htm

Artaxo, Paulo. Aquecimento Global. Revista Caros Amigos, ano XI, n. 34, set., 2007, p.4

Bodas, Cristina. Greenpeace. Assentamentos de Papel, Madeira de Lei Relatório Denúncia Parceria entre Incra e madeireiros ameaça Amazônia. 2007, 29p. Disponível em: http://www.greenpeace.org/raw/content/brasil/documentos/ amazonia/greenpeacebr_070821_amazonia_relatorio_assentamentos_incra_ port_v2.pdf

Brasil. Ministério da Ciência e Tecnologia. Inventário Nacional de Emissão de Gases do Efeito Estufa, 2004. Disponível em www.mct.gov.br

. Ministério do Meio Ambiente. Decreto $n^{0}$ 6321, de 21 de dezembro de 2007. Dispõe sobre ações relativas à prevenção, monitoramento e controle do desmatamento no Bioma Amazônia. Disponível em: http://www.planalto.gov.br/ CCIVIL/Ato2007-2010/2007/Decreto/D6321.htm

Carta Capital. 31.10.2007, ano XII, n. 468.

CordeIro, Jorge. Briefing do relatório Mudanças do Clima, Mudanças no Campo, que detalha o papel da agricultura nas mudanças climáticas. Greenpeace, 2008. Disponível em: http:/www.greenpeace.org/brasil/greenpeace-brasil-clima/ documentos/briefing-do-relat-rio-mudan-as

Cotta, Catherine; Romine Grace. Greenpeace. Brasil. Face a Face com a Destruição: Relatório Greenpeace sobre as Companhias Multinacionais Madeireiras na Amazônia Brasileira. Greenpeace: Brasil, 1999, 32p. Disponível em: http://www.greenpeace.org.br/amazonia/face_destruicao.pdf 
Domingos, João e Francisco, Nelson. Desmatamento na Amazônia dispara e põe governo em alerta. Foram derrubados $3.223 \mathrm{~km}^{2}$ de floresta de agosto a dezembro: total pode chegar a 15 mil km² em doze meses. Jornal O Estado de São Paulo, São Paulo, 24.01.2008, Caderno Vida \&. Disponível em:

http://www.estado.com.br/editorias/2008/01/24/ger-1.93.7.20080124.13.1.xml

Flannery, Tim. Os Senhores do Clima. Rio de Janeiro: Record, 2007.

Foster, John Bellamy. A Ecologia de Marx, Materialismo e Natureza. Rio de Janeiro: Civilização Brasileira, 2005.

março, 2007.

. A Ecologia da Destruição. In.: Revista Eletrônica O Comuneiro, no 4 ,

Disponível em: http://www.ocomuneiro.com/nr4_01_artigos_JOHN_BELLAMY.html

GArciA, Rafael. Jornal Folha de São Paulo, São Paulo, 22.01.2008, Ambiente. Disponível em:

http://www1.folha.uol.com.br/folha/ambiente/ult10007u365782.shtml.

Greenpeace Internacional, Holanda. Devorando La Amazônia. 2006. Disponível em: http://www.greenpeace.org/raw/content/espana/reports/devorando-laamazonia.pdf

GREENPEACE. BRASIL (R)evolução Energética: perspectivas para uma energia global sustentável. Geográfica: 2007, p.98. Disponível em:

http://www.greenpeace.org/brasil/documentos/energia/greenpeacebr_070202_ energia_revolucao_energetica_brasil_port_v1

. Greenpeace, notícias, 2008.

Disponível em: http://www.greenpeace.org/brasil/greenpeace-brasil-clima/ noticias/mudan-as-do-clima-mudan-as-no

Instituto Sociedade, População e Natureza. ISPN. Cana de Açúcar avança em áreas prioritárias para conservação e uso sustentável do cerrado. Disponível em: http://www.ispn.org.br/LevantamentoSite.pdf

Lubchenko, Jane. Aquecimento Global e Mudança Climática Global. In.: GonçAlves, CArlos Walter Porto, Revista Sem Terra, ano X, n. 36, nov-dez/06, p. 42

Marengo, José A. Mudanças Climáticas Globais e seus Efeitos sobre a Biodiversidade: caracterização das alterações climáticas para o território brasileiro ao longo do século XXI. Brasília: Ministério do Meio Ambiente, 2006.

Marquesini, Marcelo; Mugiatti, André; Adario, Paulo. Greenpeace, Brasil. Faltou Ação ao Plano de Ação. Relatório sobre as ações de governo para combater o desmatamento na Amazônia no período de março de 2004 a maio de 2005. Greenpeace, Brasil: 2005. 
Disponível em: http://www.greenpeace.org.br/amazonia/pdf/Fata_acao_web3.pdf Melo, João Alfredo Telles (org.). Reforma Agrária Quando? CPI mostra as causas da luta pela terra no Brasil. Brasília: 2006.

MST. A Reforma Agrária que virou Plano de Manejo. MST: 2007 In.: http:// www.mst.org.br/mst/pagina.php?cd=4631

- Posição da Via Campesina Internacional sobre o Aquecimento Global e os Agrocombustíveis. MST:2007.

Disponível em: http://www.mst.org.br/mst/pagina.php?cd=4517

NePstad, Daniel. Os ciclos viciosos da Amazônia: estiagem e queimadas na floresta estufa. WWF Internacional, Gland/Switzerland, 2007, 24p. Disponível em www.wwf.org.br/informacoes/index.cfm?unewsID+10881.

NetTo, Andrei. Impacto de mudança climática é 'irreversível' In.: Jornal O Estado de São Paulo, São Paulo, 17.11.2007, Caderno Vida \&. Disponível em:

http://www.estado.com.br/editorias/2007/11/17/ger-1.93.7.20071117.8.1.xml

Nobre, Carlos. A Amazônia e o carbono atmosférico. In.: Scientific American Brazil, ed. 6, nov. 2002. Disponível em: http://www2.uol.com.br/sciam/ reportagens/a_amazonia_e_o_carbono_atmosferico.html

O Estado de São Paulo. Revista Amazônia Ainda é possível salvar? São Paulo: O Estado de São Paulo, nov./dez./2007. Ver: http://www.estadao.com.br/amazonia/

ONU. Programa das Nações Unidas para o Desenvolvimento (PNUD). Relatório de Desenvolvimento Humano 2007-2008 - Combater a mudança do clima: Solidariedade Humana em um mundo dividido. GC - Gráfica de Coimbra Lda, 402p. Disponível em: http://www.pnud.org.br/rdh/

Ricardo, Beto e CAmpanili, Maura (Organização). Instituto Socioambiental Almanaque Brasil Sócioambiental. Editora Instituto Socioambiental: 2007

SAlomon, Marta. Com estímulo oficial, floresta vira capim. Jornal Folha de São Paulo. São Paulo, 13 de janeiro de 2007, Caderno de Ciência. p. A31. Disponível em:_http://www1.folha.uol.com.br/fsp/ciencia/fe1301200804.htm

Smeraldi, Roberto; May, Peter H. O. Reino do Gado. Uma nova fase na pecuarização da Amazônia São Paulo: Amigos da Terra Amazônia Brasileira: 2008. 40 p. Disponível em: http://www.amazonia.org.br/arquivos/259381.pdf

Smith, Pete; Bellarby, Jessica; Foereid, Bente; Hastings Astley. Greenpeace, 2008. Mudanças do Clima, Mudanças no Campo: impactos climáticos da agricultura e potencial de mitigação. Greenpeace Internacional: 2008. Disponível em: www.greenpeace.org/brasil/greenpeace-brasil-clima/noticias/mudan-as-doclima-mudan-as-no 
TAVES, Rodrigo. Devastação da Amazônia volta a crescer: queimadas em áreas de floresta sobem $30 \%$ este ano em relação a 2006 e serrarias operam a todo vapor. Jornal O Globo, Rio de Janeiro, 23.09.2007.

TeiXeIRA, Gerson. O Programa de Aceleração do Crescimento e o Meio Ambiente, 2007. Mímeo.

Veríssimo A; Barreto P.; TARifa R; Uhl C. Extraction of a high-value natural resource from Amazon: the case of mahogany. Forest Ecology and Management 72: 39-60.

WWF-Brasil. Agenda Elétrica Sustentável 2020: estudo de cenários para um setor elétrico brasileiro eficiente, seguro e competitivo. 2. Ed., Brasília: 2007.

ACANDLETOGOD, ANOTHER TOTHEDEVIL:THEBRAZILIAN GOVERNMENT (UN)SUSTAINABLE POLICY FOR CLIMATE CHANGE AND THE RESPONSE OF CIVIL SOCIETY

Abstract: The article analyses the environmental policy developed by the government of president Lula da Silva, in its interface with the development policy and proposals to the issue of climate change, with emphasis on the question of global warming, from the last report of the Intergovernmental Panel of Climate Change (IPCC) and its impact on Brazil. This approach focuses on the issue of the Amazon, in view of the importance of preservation of the forest, not only for being a huge sink for carbon dioxide, but also to the climate system and the rains across South America. It must not be forgotten, however, that it not longer deserves special treatment, considering the issue of energy matrix, included in the so-called growth acceleration plan (PAC). This also values the proposals of social and ecological movements, as protagonists for the defense of the forest.

Key words: Environment. Climate Change. Environmental Policy. Amazon. 